\title{
Dimensión integral e interdisciplinaria del concepto de comportamiento del consumidor
}

\author{
Cleysi Yumara Gil Hernández ${ }^{* *}$ \\ Isabel Cristina Torres Estrada*** \\ Zulima Azeneth López Torres ${ }^{* * * *}$
}

Recibido: 15 noviembre de 2012 - Aprobado: 23 de enero de 2013

\section{Resumen}

Este artículo busca analizar el aporte teórico que la economía, la antropología, la psicología, la sociología y la estética hacen al estudio del concepto de comportamiento del consumidor.

El estudio del comportamiento del consumidor debe buscar una mirada integral, que permita, desde diferentes saberes y disciplinas, comprender al sujeto, su entorno y sus prácticas de consumo.

El estudio del consumidor no debe supeditarse exclusivamente a los momentos del consumo; su comprensión implica un análisis interdisciplinar, en tanto los consumidores están inmersos en entornos sociales, económicos y culturales, que sin duda influyen en sus decisiones.

Palabras clave: Comportamiento del consumidor, Interdisciplinariedad, ciencias sociales, consumo, consumidor.

* Este artículo es resultado del macroproyecto de investigación de la fundamentación teórica del concepto de comportamiento del consumidor desde la economía, la antropología, la sociología, la psicología y la estética. Esta investigación también se nutre de los resultados de los trabajos de grado de estudiantes de pregrado de la Facultad de Publicidad, complementado con investigación documental alusiva a los tópicos tratados.

** Publicista de la Universidad Pontificia Bolivariana. Estudiante de la Especialización en Gerencia de Mercadeo y Pasante de investigación del grupo de investigación EPILIÓN- Facultad de Publicidad - Universidad Pontificia Bolivariana. Email: cley_twice@hotmail.com

*** Publicista, Magíster en Desarrollo. Docente, Coordinadora del Grupo de Investigación EPILIÓN- Facultad de Publicidad- Universidad Pontificia Bolivariana. Coautora del libro: Principios y prácticas de la publicidad, publicado en 2011. Email: isabel.torres@upb.edu.co.

**** Psicóloga, Mg. en Antropología. Docente, coordinadora línea consumo y entorno del grupo de investigación EPILIÓN. Facultad de publicidad - Escuela de Ciencias Sociales Universidad Pontificia Bolivariana. Email: zulima.lopez@upb.edu.co 


\title{
Integral and Interdisciplinary Dimension of Consumer Behavior Concept
}

\begin{abstract}
This article intends to analyze the theoretical contribution that economy, anthropology, psychology, sociology, and aesthetics make to the study of consumer behavior concept.

Consumer behavior study should look for an integral view which allows, from different areas and disciplines, to understand the subject, his/her environment, and his/her consumption practices.

Consumer study should not be exclusively subject to consumption moments; its understanding implies an interdisciplinary analysis, because consumers are immersed in social, economic, and cultural environments, which undoubtedly influence his/her decisions.
\end{abstract}

Key words: Consumer behavior, interdisciplinary, social sciences, consumption, consumer. 


\section{Introducción}

El mercadeo ha estudiado el tema del comportamiento del consumidor, con el fin de comprender el proceso de compra, de toma de decisiones y en general lograr comprender el consumo; al respecto Schiffman, L.G. y Kanuk, L.L. (1997) plantean que:

Este campo tiene sus raíces en el concepto de mercadotecnia, estrategia que surgió a fines de los cincuenta. Cuando terminó la 2a Guerra Mundial, los mercadólogos encontraron que podían vender a los consumidores casi cualquier artículo que pudieran producir, y de los que se habían visto privados cuando todas las instalaciones de producción del país se dedicaban a la fabricación de material de guerra (p. 11).

Sin embargo, los cambios en la relación oferta-demanda llevaron al mercadeo a la tarea de preguntarse primero por los deseos del consumidor, que por los bienes y servicios que la industria debía producir. Por lo anterior, el concepto de comportamiento del consumidor se ligó estrechamente con el de investigación de mercados, debido a la necesidad de comprender los procesos de compra y consumo de los públicos.

Dentro de este contexto, el campo del comportamiento del consumidor se pregunta por los deseos y necesidades de las personas, en tanto protagonistas en la escenificación del mercado y, en un fin último, las que interactúan con el marketing. Es por esto que resulta difícil estudiar, desde una sola perspectiva, un área donde las personas son el punto de partida; y al respecto Michael Solomón (2008) plantea que: "El comportamiento del consumidor cubre muchas áreas: es el estudio de los procesos que intervienen cuando una persona o grupo selecciona, compra, usa o desecha productos, servicios, ideas o experiencias para satisfacer necesidades y deseos" (p. 7).

En el afán por descifrar los anhelos de los consumidores, los mercadólogos se han dado cuenta de que estos son "[...] individuos muy complejos, sujetos a una diversidad de necesidades psicológicas y sociales muy independientes de sus necesidades de supervivencia" (Schiffman, L.G. y Kanuk, L.L., 1997, p. 12). Por tanto, el estudio del consumidor no debe supeditarse exclusivamente a los momentos del consumo; su comprensión implica un análisis interdisciplinar, en tanto los consumidores están inmersos en entornos sociales, económicos y culturales, que influyen en sus decisiones.

Esta dimensión integral del concepto de comportamiento del consumidor es evidente cuando se hace una lectura del consumo más allá de la adquisición del bien, y cuando se comprende que:

[...] La gente no compra productos por lo que hacen, sino por lo que significan. Este principio no significa que las funciones básicas de los productos no sean importantes, sino que los papeles que los productos tienen en nuestras vidas van más allá de las tareas que desempeñan (Solomon, 2008, pág. 14).

Sin lugar a dudas, el mercadeo se ha preguntado por el consumidor con el fin de cumplir unos objetivos económicos, pero de forma paralela surge la pregunta por la ética en el estudio del consumidor, concepto vinculado por Schiffman, L.G. y Kanuk, L. L. (1997)

Anagramas Volumen 11, № 22 pp. 179-200 ISSN 1692-2522 Enero-Junio de 2013. 208 p. Medellín, Colombia 
al de mercadeo social, argumentando que las empresas "deben satisfacer las necesidades y deseos de sus mercados objetivos en formas que preserven e incrementen el bienestar de los consumidores y la sociedad como un todo" (p. 19).

De acuerdo con lo anterior, para emprender acciones de mercadeo social, se debe conocer e interpretar la esencia y el entorno de los consumidores, de tal forma que se puedan advertir las implicaciones propias del accionar del mercadeo. Sin embargo, las prácticas responsables hacia el consumidor no pueden estar vinculadas exclusivamente a las causas sociales; el consumidor demanda cada vez más de las organizaciones la implementación de acciones tendentes a su protección y, por tanto, el impacto de las prácticas económicas de las mismas deben aportar favorablemente a los contextos socio-culturales de dicho consumidor. En este orden de ideas, el estudio del concepto del comportamiento del consumidor debe buscar una mirada integral, que le permita, desde diferentes saberes y disciplinas, comprender al sujeto, su entorno y sus prácticas de consumo.

Esto hace evidente la necesidad de establecer vínculos en el estudio del comportamiento del consumidor con otros saberes y disciplinas, de tal forma que desde el mercadeo sus aplicaciones sean más acertadas, en tanto permitan ajustarse a las dinámicas de consumo y que respondan a los contextos socioculturales de los públicos.

\section{Metodología}

El presente artículo es una revisión de resultados derivados de la investigación realizada sobre el aporte teórico que desde diferentes disciplinas se ha hecho a la fundamentación del concepto del comportamiento del consumidor.

Esta investigación es cualitativa, y con este fin, se utilizó como método de recolección de información la investigación documental, la cual inició con autores clásicos como Karl Marx, Max Weber y Émile Durkheim como herramienta en sus estudios y como un componente clave en el proceso de la investigación y en la triangulación de la información. De esta manera, María Eumelia Galeano Marín (2009) expone que la investigación documental es una técnica de recolección y validación de la información que combina diversas fuentes (primarias y secundarias) y que, además, en la revisión del contenido pueden combinarse la entrevista, el cuestionario, la observación, entre otras.

Para estructurar el contenido del artículo, en primer lugar, se hizo necesario partir de una rigurosa revisión de fuentes bibliográficas, que permitió encontrar el estado del arte del tema, sus orígenes, evolución, las principales teorías y planteamientos, tanto desde el mercadeo como desde las demás disciplinas estudiadas.

En segundo lugar, se hizo la revisión de trabajos de grado de pregrado de la Facultad de Publicidad y de Psicología, en los que se hicieron entrevistas en profundidad a expertos y/o representantes de la antropología, la psicología, la estética y la sociología, vinculados profesionalmente a los procesos de mercadeo y a la planeación publicitaria en diferentes empresas; esto con el fin de comprender y de proponer alternativas para la consolidación teórica y metodológica de este campo de estudio. 


\section{Resultados}

\section{Dimensión interdisciplinar del concepto de comportamiento del consumidor}

Entre las décadas de los 30 y los 50 las empresas empiezan a preocuparse por el comportamiento de sus públicos e inician procesos incipientes de indagación en torno a los comportamientos de sus clientes. Sin embargo, es a partir de los años 60, posterior a la Segunda Guerra Mundial, cuando el concepto toma más fuerza y la relación entre oferta y demanda cambia, lo cual lleva a las organizaciones a orientar su enfoque de ventas hacia el consumidor y no hacia la producción como tradicionalmente venía haciéndose.

Este interés por el consumidor desde el mercadeo fue desvelando la necesidad de estudiar el concepto más allá del momento de compra; su comprensión implicaba un análisis interdisciplinar del consumo y del consumidor desde "[...] la psicología (estudio del individuo), la sociología (estudio de los grupos), la psicología social (la forma en que un individuo se interrelaciona dentro del grupo), la antropología (influencia de la sociedad sobre el individuo) y la economía" (Rivera, Arellano \& Molero, 2009, p.23).

Schiffman, L.G. y Kanuk, L.L. (2010) hacen alusión al comportamiento del consumidor como un acto que va más allá de un momento de intercambio (oferta-demanda), diciendo que:

Este $[. .$.$] se enfoca en la manera en que los consumidores y las familias o los hogares$ toman decisiones para gastar sus recursos disponibles (tiempo, dinero, esfuerzo) en artículos relacionados con el consumo. Eso incluye lo que compran, por qué lo compran, cuándo, dónde, con qué frecuencia lo compran y utilizan, cómo lo evalúan después de la compra, el efecto de estas evaluaciones sobre sus compras futuras y cómo lo desechan (p. 5).

Assael (1999) comparte esta perspectiva en cuanto al conocimiento del individuo y todo lo que influye en la toma de decisiones del mismo, planteando que:

[...] Los gerentes ahora se ocupan de proporcionar beneficios a los consumidores, de aprender acerca de las actitudes cambiantes y de las percepciones de los consumidores influyentes. Así mismo, se percatan de que los planes de mercadotecnia se basan en las fuerzas psicológicas y sociales que tienden a condicionar el comportamiento del consumidor [...] (p. 4).

A partir de la comprensión del consumidor se busca fortalecer la creación de estrategias de marketing y detectar y/o satisfacer necesidades en un mercado. Es importante, entonces, reconocer que las estrategias de mercadeo nacen de un conocimiento previo de las necesidades del consumidor y su entorno (cultura); Ello implica entender y comprender aspectos tales como motivaciones, percepciones y actitudes del consumidor. Hawkins (1994) plantea un modelo general del comportamiento del consumidor (como se muestra en la figura siguiente) donde se aprecian estos factores que influyen en la conducta del consumidor: 
Figura 1

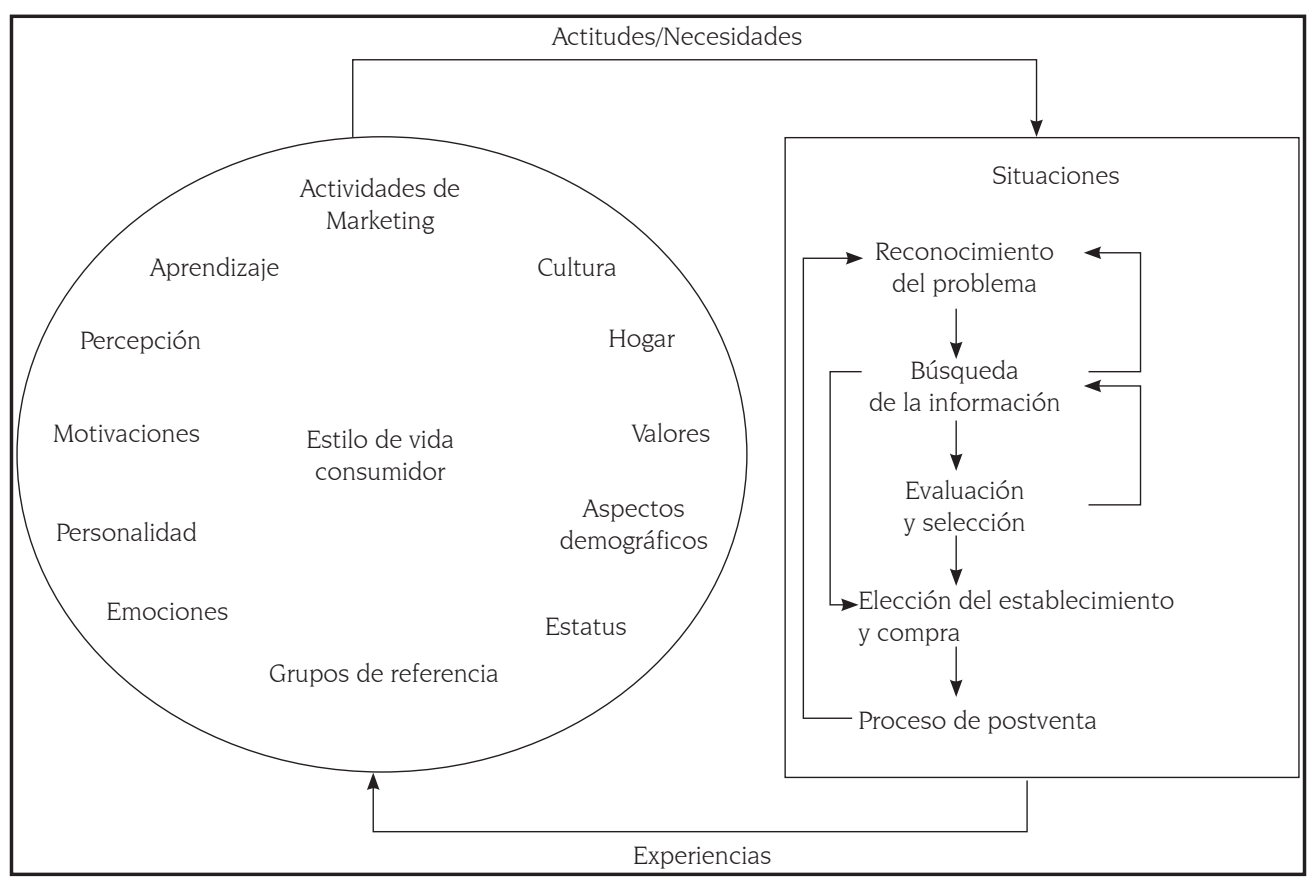

Fuente: Hawkins B. C. y Addison W. "Comportamiento del consumidor, repercusiones en la estrategia de marketing". Editorial Iberoamericana, EE. UU., 1994.

Además de factores psicológicos y sociales que influyen en el comportamiento del consumidor, Solomón (1997) indica que: "el comportamiento de los consumidores se define en gran parte por sus necesidades o deseos" (p. 8). Dichas necesidades pueden clasificarse como: fisiológicas, de seguridad y tranquilidad, sociales (amor, afecto, pertenencia y aceptación), de autoestima y de autorrealización (autosatisfacción).

La satisfacción de las necesidades desde una perspectiva simbólica se convierte en la búsqueda del bienestar que se consigue cuando una de esas necesidades se complace. En consonancia con esto, el comportamiento del consumidor no está definido como un simple intercambio (la compra/venta de un bien y un servicio), sino como un conjunto de fuerzas sociales, culturales y psicológicas que motivan al consumidor a tomar una decisión de compra y un conjunto de necesidades que determinan su comportamiento.

El estudio del concepto del comportamiento del consumidor es complejo y requiere del análisis de factores internos y externos al individuo. Por esto se dice que su abordaje es interdisciplinar y se retroalimenta con áreas que analizan el comportamiento del individuo desde diversas perspectivas. De este modo Peter E Olson (2006) reconocen la interdisciplinariedad del concepto del comportamiento del consumidor, retomando el significado que da la American Marketing Association, la cual lo define como: "La interacción dinámica de los efectos y cognición, comportamiento, y el ambiente, mediante la 
cual los seres humanos llevan a cabo los aspectos de intercambio comercial de su vida" (Citado por Peter E Orson, 2006, p. 5).

A partir de esta definición los autores en mención plantean que el comportamiento del consumidor es dinámico porque el consumidor se encuentra en un ambiente cambiante, y por esto se modifican sus percepciones y sus conductas. Es así como estos autores exponen que:

El ambiente del consumidor es todo factor externo a éste, el cual influye en su manera de pensar, sentir y actuar. Ello abarca estímulos sociales, como las acciones de otros en culturas, subculturas, clases sociales, grupos de referencia y familias, que influyen en los consumidores. También comprende otros estímulos físicos, como las tiendas, productos, anuncios y letreros, que pueden cambiar los pensamientos, sentimientos y acciones de los consumidores (Peter $\mathcal{E}$ Orson, 2006, p. 25).

El concepto del comportamiento del consumidor se nutre así del aporte de diferentes áreas de conocimiento que permiten explicar y conocer la conducta de los consumidores en todo el proceso de compra y de toma de decisiones, con el fin de generar estrategias de marketing que favorezcan las decisiones empresariales.

\section{Aporte de la economía en el estudio del comportamiento del consumidor}

Robbins (1932) considera la economía como una ciencia social, que analiza cómo los seres humanos satisfacen sus necesidades ilimitadas con recursos escasos que tienen diferentes usos.

A partir de esta premisa es conveniente caracterizar, desde la perspectiva económica y del mercadeo, cinco fases históricas acerca del origen y desarrollo hasta la actualidad del marketing, las cuales muestran a través de diferentes períodos importantes en la Economía el enfoque de la producción de bienes y servicios, y permiten analizar la importancia que se le ha otorgado al estudio del consumidor durante estas fases. De esta manera, Schultz, Tannenbaum $\mathcal{E}$ Lauterborn (1992) exponen que estas fases son:

1. Segunda Guerra Mundial. Al estallar la Segunda Guerra Mundial todo cuanto existiera giraba en torno a la guerra: los periódicos, las revistas, los carteles, los noticiarios, las oficinas, y por supuesto las fábricas (y productos). El énfasis de la producción estaba centrado en bienes cuya función principal era servir de instrumentos para la guerra y no en las necesidades de los consumidores.

2. El héroe manufacturero. Al terminar la guerra, las fábricas fueron reconvertidas rápidamente, y su éxito radicaba en la capacidad de producción (masiva y en serie). La publicidad mostraba la nueva vida después de la guerra, era el momento de fabricar todos aquellos productos de los que las personas se habían visto privados a causa de la guerra. En esta etapa quienes producían no se preocupaban por hacer un estudio previo identificando las necesidades de los consumidores y los productores consideraban que cualquier producto simplemente podía venderse.

3. Marketing masivo. En los 50 el marketing se usó en esta fase para vender aquellos bienes estandarizados, los manufactureros consideraban que el público era una masa 
de personas sin criterio; por ende, se pensaba que mucha publicidad movía mucha mercancía. En 1960 se empezó a cuestionar el modelo de producción en serie de Henry Ford (fordismo).

4. Desmasificación. En esta fase empiezan a surgir teorías como la de Jack Trout y Al Ries en 1972 sobre el posicionamiento, desvirtuando otras teorías de marketing que concebían los productos muy aislados de los consumidores; Trout y Ries, empezaron a darle importancia a lo que pensaba el consumidor.

5. El poder del consumidor. En los 90 empiezan a darse una serie de cambios que el marketing debe interpretar, como la variación en la tipología de familia tradicional, el nivel de educación y la información a la cual tienen acceso los consumidores, la concepción y la adopción de nuevos estilos de vida. Este poder del consumidor significa entonces, que las personas eligen qué quieren ver, escuchar y comprar. A partir de esto, algunas empresas empiezan a preocuparse por estudiar al consumidor y por responder a sus gustos, deseos, anhelos y preferencias.

Actualmente existe una preocupación por el consumidor, que ha llevado a las empresas a preguntarse cómo se comporta, qué le gusta y qué quiere. El economista Esteban Carlos Mejía (2011) en entrevista expone que están "[...] mirándose los productos desde el punto de vista de quién los consume" y esto "[... es un triunfo del consumidor, él va a definir lo que ocurra en la producción, es él quién decide qué se va a producir y qué productos permanecen o salen del mercado". Respecto a este tema, Verdú (2003) habla de un capitalismo de ficción que tiene sus inicios en los 90 en Estados Unidos. El consumo no se enfoca en los productos sino en las experiencias y sensaciones. Se da el culto al cuerpo, se promociona la experiencia de vida extrema, el entretenimiento, la fantasía y la tecnología como ejes principales en el mercadeo y la publicidad. La realidad del hombre es retomada como insumo para la ficción y es utilizada para la publicidad y para la creación de nuevos productos/servicios.

Cabe señalar que este recorrido histórico está ligado al concepto de segmentación el cual es definido por Valiñas (2002) como "[... Una herramienta de mercadotecnia que ayuda a comprender el comportamiento el consumidor, que se define como la partición y conformación de subgrupos de personas con al menos una característica homogénea, a partir de un grupo o universo heterogéneo." (p.76).

Se debe comprender entonces que en los años 50 la teoría económica estaba centrada en la producción de bienes en serie o estandarizados y los productores asumían que los consumidores tenían las mismas necesidades, de aquí que el concepto de segmentación aún estaba alejado del estudio de las necesidades de los consumidores. Este modelo de economía se ha conocido como fordismo, gracias a los planteamientos de la producción de Henry Ford. Pero es a partir del posfordismo cuando se hace necesario empezar a determinar grupos homogéneos de consumidores y se empieza a utilizar la segmentación, ya que es a partir de esta cuando las empresas entienden que todos los consumidores tienen necesidades, gustos e intereses diferentes. 
De este modo diversos autores desde la economía han aportado teóricamente a la segmentación, puesto que se ha convertido en una de las premisas importantes para analizar el comportamiento del consumidor. Por ejemplo, para Solomon (2008) "[...] las personas se clasifican en términos de su posición relativa en la sociedad, la cual determina el acceso que tienen a recursos como la educación, la vivienda y los bienes de consumo" (p. 456)

Ciertamente el consumo genera una jerarquización social; por esto la importancia de hablar de clases sociales de acuerdo con esos aspectos moldeados por el consumo como los gustos e intereses, los estilos de vida y la estructuración jerarquizada de la sociedad. Para Dubois (1998) las clases sociales "[...] son: grandes conglomerados, jerarquizadas, evolutivas, multidimensionales pero relativamente homogéneas" (p. 126)

Con respecto a las clases sociales, el ingreso es una de las variables socioeconómicas utilizadas para acercarse y entender el concepto de clase social como lo mencionan Shiffman $\mathcal{E}$ (2010). De acuerdo con el ingreso, las personas pueden distribuir su riqueza según sus necesidades, o aún más importante, sus gustos, lo cual es de vital importancia en las investigaciones del comportamiento del consumidor; saber qué quieren, cómo van a gastar su dinero y qué tipo de productos o servicios se les puede ofrecer en torno a su ingreso. De esta manera, la economista Lina Restrepo (2011), perteneciente al área de mercadeo e investigaciones de Vajillas Corona (en entrevista), expone que el consumidor se somete a una evaluación de alternativas, y según su ingreso, el precio puede convertirse en un detonante o en un inhibidor de la compra.

A pesar de que el nivel de ingresos de alguna manera condiciona el consumo, en algunas ocasiones el consumidor se desprende de esto para conseguir lo que quiere; es así como cambian las prioridades del consumo y la asignación de presupuestos con el fin de obtener objetos y/o pertenecer a una comunidad.

Alrededor del tema la docente e investigadora de mercados María Cecilia Calderón (2011) en entrevista expone que "[...] a finales de los 80 y a principios de los 90 se empieza a segmentar por estilos de vida"; y se tiende a combinar estos criterios con los elementos tradicionales de segmentación (ciudad, estrato o clase social, edad, etc.). Calderón (2011) también dice que "[...] en el siglo XXI empieza a tener mayor relevancia el concepto de afinidades, y se ha trabajado con el concepto de "comunidades", que son los criterios y afinidades que unen un grupo. Este tipo de segmentación actual se trabaja respondiendo a preguntas como: nivel de apropiación, nivel de inversión, su afinidad, nivel de conocimiento".

A partir de estos criterios económicos, el estudio del comportamiento del consumidor se puede caracterizar por un énfasis limitado, y por proponer básicamente el intercambio racional de bienes y servicios para satisfacer unas necesidades de unos grupos "homogéneos". "[...] Se supone que el consumidor escoge entre las alternativas que le ofrece el mercado de una manera racional y en función de sus limitados recursos para alcanzar un cierto grado de bienestar" (Rivas, 2001, P. 50). En consecuencia, la satisfacción de necesidades de una manera racional propone un modelo que sugiere que el consumidor 
durante un momento de compra pasa por un proceso de elección, que hace alusión a preferencias y restricciones ligadas al precio y la utilidad.

Sin embargo, es a partir de los 90 cuando empieza a dársele mayor importancia al estilo de vida de los consumidores: cómo piensan, qué quieren, qué les gusta, cuáles son sus intereses, en qué invierten su esfuerzo y su dinero, etc., y esto permite empezar a involucrar otros criterios que abarcan el estudio del comportamiento del consumidor desde otras perspectivas.

Para el estudio del comportamiento del consumidor, la economía propone teorías que exponen que el consumidor es un sujeto racional que optimiza recursos, tiene gustos y preferencias en cuanto a la elección de bienes y servicios que satisfacen sus necesidades y que, además, esta elección es restringida por sus ingresos.

Estas teorías económicas dan pautas para segmentar, pero a la vez necesitan de complementos teóricos, conceptuales y prácticos de otras ciencias sociales que permitan analizar al consumidor de manera de holística.

\section{Aporte de la antropología en el estudio del comportamiento del consumidor}

La antropología es la ciencia social que estudia de manera holística el ser humano y su comportamiento dentro del marco de la sociedad y la cultura a la que pertenece. La antropología a su vez permite "[...] el estudio comparativo de la humanidad; sus objetivos son describir, analizar y explicar tanto las similitudes como las diferencias entre los grupos humanos [... ]" (Nanda, 1980, p. 4).

Para el estudio del concepto del comportamiento del consumidor, una de las subdisciplinas de la antropología que debe retomarse es la antropología cultural, que básicamente se ocupa de la descripción y el análisis del comportamiento de los individuos dentro de una cultura y sus estructuras sociales. Geertz (1973) define la cultura como un concepto semiótico:

[...] Creyendo con Max Weber que el hombre es un animal inserto en tramas de significación que él mismo ha tejido, considero que la cultura es esa urdimbre y que el análisis de la cultura ha de ser por lo tanto, no una ciencia experimental en busca de leyes, sino una ciencia interpretativa en busca de significaciones (p. 20).

Desde el ámbito del consumo, diversos autores han estudiado cómo la cultura ejerce influencia sobre el comportamiento del consumidor, y cómo este se rige por significados simbólicos que se le otorgan a determinados objetos (productos) dentro de una cultura. Las personas aprehenden un conjunto de símbolos haciéndolos suyos que sirven para describir su mundo (su vida), expresar sus ideas y sus sentimientos. "A diferencia del consumo a la antigua, los actos de compra en nuestras sociedades expresan ante todo las diferencias de edad, los gustos particulares, la identidad cultural y personal de los agentes, incluso a través de los productos triviales" (Lipovetsky, 2007, pág. 39).

La publicista y magíster en Antropología, Beatriz Elena Álvarez (2011), en entrevista, expone que -desde la antropología- el estudio del comportamiento del consumidor se piensa como el entendimiento de la conducta de las personas ante una marca o producto 
permeado por la cultura. Existen aspectos dentro de las culturas como por ejemplo el prestigio, la elegancia, etc., que modifican el tipo de productos que se consumen no solo por su función, sino también por su significado. Es por esto que este entendimiento del consumidor se puede analizar a través del simbolismo atribuido a marcas o productos, y de la visualización del consumo como proceso colectivo y social. Assael (1999) e xpone que:

[...] La cultura afecta el comportamiento de compra, pues refleja los valores que los consumidores aprenden de la sociedad - como la individualidad, la independencia, el logro y la autorrealización-. Como plantea el historiador Daniel Boorstin, los estadounidenses del siglo XX se asocian entre si no tanto por sus creencias políticas o religiosas, sino por lo que consumen. Por lo tanto las compras y las posesiones de los consumidores son el reflejo de la cultura (p. 441).

El consumo, como reflejo de la cultura, significaría entonces que no se compran productos por su utilidad sino por el significado simbólico otorgado a estos. "[...] La relación del consumidor con el objeto se ha modificado: no se trata ya de un objeto y su utilidad específica, sino de un conjunto de objetos en su significación total". (Baudrillard, 1974. P.17).

El consumo puede convertirse así en reflejo de la cultura, en tanto que se consumen productos de acuerdo con los gustos e intereses que responden a unos asuntos culturales, y es por esta razón que cuando una marca planea llegar a nuevos mercados debe estudiar y adaptarse a la cultura.

Respondiendo a estos elementos culturales, los antropólogos también se han preocupado por estudiar el Homo Economicus y han establecido la relación entre economía y cultura, "[...] un aspecto de esta interrelación es que la cultura define o moldea los fines que buscan los individuos y los medios para alcanzarlos [...]". (Nanda, 1980, p.154). La economía se encuentra inserta en la cultura y en su estructura social; por esto, no pueden separarse, porque tanto la cultura como la economía influyen en el consumidor, en sus necesidades, sus gustos, sus intereses, sus creencias, sus valores y sus elecciones en cuanto productos o marcas que satisfagan sus necesidades.

Al mismo tiempo la cultura también puede fragmentarse en subculturas, que son definidas como "[...] un sistema de percepciones, valores, creencias y costumbres que son significativamente diferentes a los de la cultura dominante" (Nanda, 1980, p.42). De acuerdo con este fraccionamiento de la cultura se debe retomar el concepto de segmentación aplicado al proceso de identificación de grupos o subgrupos de personas con características homogéneas entre ellas o que las diferencien de otras.

Nanda (1980) plantea una especialización de la cultura, en la que se comparten patrones culturales (para hablar de diferencias entre culturas o subculturas), como por ejemplo la repartición sexual del trabajo, en la que los hombres pueden hacer trabajos que las mujeres no; la edad, el lenguaje, la música, la conducta, los rituales son aspectos que separan unos grupos o subgrupos de otros. Estas especializaciones de la cultura deben tenerse en cuenta al momento de segmentar públicos, como parámetro clave para un planteamiento adecuado de la estrategia de mercadeo. 
[...] Los mercadólogos deben estudiar la(s) cultura(s) específica(s) de sus mercados meta potenciales para determinar si sus productos serán aceptables por sus miembros, en caso de ser así, cuál es la mejor manera de comunicar las características de sus productos para persuadir al mercado meta de comprarlos (Schiffman, L.G. y Kanuk, L.L., 2010, p.354).

Para sintetizar, es importante hablar de la cultura como soporte para la creación y gestión de estrategias de marketing porque desde esta perspectiva una empresa puede adaptarse a necesidades específicas según aquellas estructuras sociales definidas por una la cultura de determinado nicho.

\section{Aporte teórico de la sociología en el estudio del comportamiento del consumidor}

La sociología "estudia los individuos, los grupos y las interacciones humanas". (Rivas, 2001, p 34). A partir de estos conceptos el consumo puede ser contemplado como un acto colectivo, que exige estudiar al consumidor como un ser social regido por aquellas interacciones sociales que así lo definen.

Baudrillard (1974) integra al concepto de consumo una mirada sociológica diciendo que: "El consumo es una conducta activa y colectiva, es una obligación, es una moral, es una institución. Es todo un sistema de valores con que dicho término implica como función de integración del grupo y de control social" (p. 119).

El consumo como un acto colectivo significa a aquel consumidor dentro de una sociedad; lo que Baudrillard (1974) llama la sociedad de consumo, que

Es también la sociedad de aprendizaje del consumo, de adiestramiento social al consumo, es decir, un modo nuevo y específico de socialización, en relación con la aparición de nuevas fuerzas productivas y la reestructuración de un sistema económico de elevada productividad (p. 119).

A partir de este adiestramiento social al consumo que propone Baudrillard (1974), es conveniente recurrir a conceptos de la sociología como lo son la comunidad, el grupo y la familia, que permitan estudiar el comportamiento del consumidor desde aquellas estructuras sociales que intervienen en su comportamiento. En primer lugar para la sociología una comunidad es:

Un subgrupo que tiene muchas características de la sociedad, pero en pequeña escala y con intereses comunes menos amplios y coordinados. Implícito en el concepto de comunidad encontramos un área territorial, un grado considerable de conocimiento y contacto interpersonal y cierta base especial de cohesión que la separa de los grupos vecinos (Fairchild, 1944, pág. 53).

En la comunidad prevalecen los intereses colectivos, y es por esto que los comportamientos de los individuos son regulados de acuerdo con ellos. Por su parte, el grupo es más pequeño, y es definido como "[...] dos o más personas entre las que existe una pauta establecida de interacción psicológica; se reconoce como una entidad por sus propios miembros y, por regla general, por los demás, en razón del tipo particular de conducta colectiva que representa" (Fairchild, 1944, pág. 133). Así que los intereses y gustos de un individuo pueden definirse o redefinirse en la interacción con el grupo en el que está 
inmerso; y será este quien determine qué productos y servicios son aptos para alcanzar esos objetivos colectivos.

Al conceptualizar y definir los grupos sociales, es indispensable remitirse al núcleo principal de la sociedad, la familia. "[...] En un sentido muy dinámico los individuos que constituyen una familia se definen como los miembros del grupo social más fundamental, quienes viven juntos e interactúan con la finalidad de satisfacer sus necesidades personales y recíprocas" (Schiffman, L. G. y Kanuk, L. L., 2010, p. 300).

La familia, desde el marketing, se define como el núcleo o grupo de individuos primordial de consumidores, que buscan satisfacer unas necesidades y "[...] que sirve como referencia para que el individuo forje sus creencias, actitudes y comportamientos" (Assael, 1999, p. 513). En esta formación y aprendizaje del individuo se crea una relación de la familia con el consumo, y respecto a esto la docente Paula Andrea Osorio Villa (2001) en entrevista expone que "[...] La influencia que tienen ciertos productos en el comportamiento social o en el comportamiento individual o familiar es porque generan cierta identificación, y esto genera patrones o roles particulares [...]".

Este proceso de formación del individuo dentro de un núcleo familiar, hace parte del proceso de socialización, que "[...] es una función familiar esencial. En el caso de los infantes consiste en compartirles los valores básicos y las normas de comportamiento congruentes con su cultura" (Schiffman, L. G. y Kanuk, L. L., 2010, p. 305).

Schiffman, L. G. y Kanuk, L. L. proponen, además, un modelo del proceso de socialización que muestra cómo influye la sociedad y la familia sobre el comportamiento de consumidor. La familia ejerce influencia en los valores y en los comportamientos fundamentales, como principios morales y religiosos, habilidades interpersonales, normas de aseo y vestimenta, modales y forma de hablar, motivación educativa, metas ocupacionales y normas del comportamiento del consumidor. Y la sociedad ejerce influencia en las actitudes y comportamientos más expresivos como estilo, moda, tendencias pasajeras, actualización y comportamiento aceptable del consumidor.

Por otro lado, los mercadólogos también se han preocupado para ser parte del proceso de socialización de los niños, ya que representa una oportunidad para la marca ser parte de la vida de una persona desde su infancia. Los niños dentro del aprendizaje de su cultura (hábitos, costumbres, creencias, etc.) se convierten en ese prospecto de mercado potencial.

A partir de dicho proceso de socialización, los grupos (además del familiar) pueden afectar el comportamiento de las personas. Algunos de estos grupos ejercen una influencia directa sobre el comportamiento y son a los que el individuo pertenece. Los otros grupos ejercen una influencia indirecta y son a los que el individuo no pertenece, y se les da el nombre de grupos de referencia o de aspiración, "[...] los grupos de referencia descansan sobre un mecanismo de aspiración (o de repulsión)" (Dubois, 1998, p. 111).

La naturaleza de los grupos de referencia puede ser distante o cercana, y el consumo de determinados productos puede estar determinado por estos grupos de referencia 
distantes como las estrellas de cine o deportistas, que han alcanzado un estilo deseable por los otros miembros de la sociedad y grupos más cercanos como los amigos. Según la naturaleza de los grupos, el papel desempeñado por los productos dentro de estos puede estar cargado de ciertos significados simbólicos, que incluyen o excluyen personas, y que, además, se convierten en un asunto aspiracional.

Uno de los factores importantes del grupo de referencia es la existencia de un líder o un representante significativo del grupo: "[... es el miembro de un grupo que, por sus habilidades especiales, conocimientos, personalidad u otras características, ejerce una influencia sobre los demás" (Kotler, 2005, p. 147). De esta forma, los mercadólogos han empezado a detectar a estos individuos que se convierten en un punto estratégico para las marcas, a la hora de ejercer influencia sobre los demás e incentivar el consumo de determinado producto.

En el trasfondo de la aspiración de pertenecer a un grupo se encuentra el estatus, que puede ser conseguido a través de dicha pertenencia o por el consumo de determinados productos. Baudrillard (1974) cataloga el consumo como un proceso de clasificación y de diferenciación social, anotando que en este:

Los objetos/signos se ordenan esta vez no solo como diferencias significativas dentro de un código, sino como valores de status dentro de una jerarquía. Aquí el consumo puede ser el objeto de un análisis estratégico que determina su peso específico en la distribución de los valores de status (en implicación con otros significantes sociales: saber, poder, cultura, etc.) (p. 92).

Como resultado de un consumo ligado al estatus, este empieza a tener otras significaciones sociales. Bauman (2007) expone que el consumo se convirtió en algo fundamental para la vida de las personas, en algunos casos, el propósito de la existencia y fundamento de las relaciones humanas. Se ve entonces el consumo como una alusión a la interacción social, que coordina el comportamiento de los individuos, y al individuo en su realización.

Para redondear la idea del aporte de la sociología al comportamiento del consumidor, Alonso (2005) dice que la sociología ha mostrado que la relación entre el sujeto y el consumo tiene que ver con las actividades individuales o colectivas que este realiza, de su entorno y de la cultura en que se encuentra inmerso; por esta razón ver el consumo como un comportamiento aislado o individualista resulta erróneo.

\section{Aporte de la psicología en el estudio del comportamiento del consumidor}

La perspectiva psicológica en el estudio del comportamiento del consumidor surge por las limitaciones racionalistas que proponían los economistas en décadas anteriores, las cuales suponían que las elecciones hechas por los consumidores entre un bien o servicio y otro se determinaban por procesos meramente racionales ligados a su capacidad económica. Es por esto que se hace necesario estudiar al sujeto y todas las variables internas y externas, que influyen en su comportamiento. Dogana (1984) expone que:

De manera que se afirmó así la necesidad de reconsiderar el proceder del consumo poniendo mayor atención a las variables del carácter subjetivo (necesidades, motiva- 
ciones y expectativas de naturaleza psicológica). El marketing cambió de orientación y en lugar de tener su centro en el producto se centró en el consumidor (p. 16).

En el estudio del individuo y en el análisis de cómo lo afectan aquellas variables externas, la psicología social puede nutrir y ayudar a entender cómo lo social determina al individuo en ciertos aspectos y cómo afecta su comportamiento de consumo individual. De esta manera la psicología "[...] Estudia los comportamientos individuales desde su vertiente interna. Pero los consumidores no operan en solitario, la Psicología social profundiza en el grupo en cuanto generador de fuerzas sobre el individuo" (Rivas, 2001, p. 34).

A partir de la psicología se han desarrollado teorías que se denominan como psicología del consumidor (o del consumo) y que:

[...] Prácticamente, desde su aparición como disciplina, la psicología ha aportado a la conducta del consumidor enfoques teóricos, métodos y técnicas de investigación, para responder a los múltiples problemas que plantea el estudio de la conducta del consumo: cuáles son los motivos del consumo, cómo se atiende, se percibe y recuerda la información sobre estímulos comerciales, cómo se forman y modifican las preferencias hacia productos, marcas, tiendas, anuncios, cómo se toman decisiones de consumo, por qué se ahorra, qué factores están relacionados con la fidelidad a las marcas o con la aceptación de las innovaciones, etc. (Rivas, 2001, pp. 55-56).

A este propósito es importante empezar a definir el concepto de comportamiento, para un acercamiento a esas conductas que modelan la forma de consumir de los individuos. El estudio del comportamiento del consumidor lo define Dubois (1998) como "[...] el conjunto de reacciones estables y coordinadas de un individuo como respuesta a los estímulos de su entorno [...]" (p. 33).

Es por esto que la conducta del individuo, en respuesta a estímulos del entorno, lleva a entender que el consumo adquiere un significado simbólico, que moldea comportamientos de compra y es aquí cuando los productos adquieren significados para quien los consume y de alguna manera ayudan a definir su identidad y su personalidad para diferenciarse o asemejarse a otros. Es así que el consumo comunica y proporciona información sobre la el consumidor, sus creencias, sus valores y su estilo de vida. Al llegar a este punto, se establece una relación del consumo con el concepto de personalidad; Appadurai (1991) considera que:

El consumo consiste en la apropiación de los objetos que integran la propia personalidad y que además es la etapa durante la cual los bienes se vinculan a referentes personales, cuando dejan de ser "bienes" neutrales, para convertirse en atributos de seres individuales, en insignias de identidades, y en signos de relaciones y obligaciones interpersonales específicas.

Ahora bien, es importante comprender que el concepto de personalidad también ha sido utilizado por el marketing bajo la estructura de personalidad de marca, Dogana (1984) lo explica diciendo que lo que se consume consiste también en las ideas que las personas se hacen de un producto, es decir, las configuraciones simbólicas que el consumidor se forma de este, sean estas reales o imaginarias. 
De esta forma las motivaciones de los consumidores están ligadas a la personalidad y a estímulos internos o externos que los llevan a una acción en particular como satisfacer una necesidad, un anhelo o deseo. Schiffman, L.G. y Kanuk, L. L. (2010) define la motivación define como:

La fuerza impulsora dentro de los individuos que los empuja a la acción. Esta fuerza impulsora se genera por un estado de tensión que existe como resultado de una necesidad insatisfecha. Los individuos se esfuerzan tanto consciente como subconscientemente por reducir dicha tensión eligiendo metas y valiéndose de un comportamiento que, según sus expectativas, satisfará sus necesidades y, de esa manera, aliviará el estrés que padecen. (p. 88).

Una acción humana siempre es respuesta a una motivación (motivo psicológico y/o sociológico). Según la teoría psicológica expuesta por Ferber E Wales (1969) las influencias importantes de la psicología en la motivación son:

(1) Un individuo desconoce por completo sus propios motivos; (2) Los motivos son complejos y muy a menudo en conflicto, ya que un solo acto rara vez es resultado de un solo motivo; (3) la estructura básica de la personalidad del individuo es importante como soporte de motivos; (4) las motivaciones se encuentran en varios niveles de los consciente; algunas pueden ser registradas acertadamente, pero otras muchas, no (p. 8).

En contraste con las motivaciones, las percepciones juegan un papel importante en el mercadeo. Una acción de consumo puede ser resultado de una motivación guiada por la percepción que se tiene de un producto. La percepción desempeña un papel simbólico, que constituye en últimas aquel significado atribuido por el consumo de un producto. Este contraste de motivación y percepción puede entenderse a partir del ejemplo del consumo de un vehículo que proponen Ferber \& Wales (1969). La motivación juega el papel de hacer presión psicológica sobre la necesidad de un individuo para conseguir un automóvil por razones de prestigio, y la percepción será aquella que el individuo tiene sobre determinada marca de automóvil que le ayudará a conseguir el estatus que necesita.

Además de la personalidad, las motivaciones y las percepciones, el concepto de actitud es considerado como un factor importante en el comportamiento del consumidor. Según Munné (1986) las actitudes son "el conjunto de creencias, sentimientos y tendencias de un individuo que dan lugar a un determinado comportamiento" (p. 30).

Una actitud puede ser el resultado de la mezcla entre la personalidad, la motivación y la percepción.

Puede considerarse la actitud como el homólogo psicológico de los procesos dinámicos que se desarrollan dentro del individuo y que dan por resultado la organización de su percepción de cualquier situación dada, y se manifiestan en su respuesta. Así, la elevación de una ceja o el encogimiento de un hombro indican tanto una actitud como una respuesta verbal que pretende expresar una opinión (Ferber \& Wales, 1969, p. 147).

Por otro lado, las emociones generadas por las marcas pueden influir en el acto de compra y están presentes durante todo el proceso interviniendo en la formación de las 
actitudes frente a productos o marcas, "[.. .] se considera que los motivos van acompañados a menudo de una condición de agitación del organismo, que recibe el nombre de emoción [...]" (Buzzell, Nourse, Matthews, Levitt, 1979, p. 162).

Las emociones pueden mediar la decisión de compra o el comportamiento del consumidor, pues causan sensaciones y experiencias positivas o negativas, con las que las marcas pueden ser relacionadas; de aquí que las marcas procuren generar experiencias positivas, que causen impacto y generen sensaciones efectivas o auténticas para que el consumidor las relaciones o las recuerde de esta manera:

[...] De hecho, las emociones juegan un rol tan importante en la compra porque nos llenan de razones para la elección. Asociando imágenes, músicas o símbolos fuertes, la publicidad emocional busca hacernos amar la marca con el fin de que la compremos. Con el tiempo esta se convierte en nuestra marca preferida y el colchón afectivo que le ponemos alrededor la protege contra cualquier eventual sustitución (Dubois, 1998, p. 89).

En concordancia con lo planteado, la psicología permite un acercamiento al individuo y a su accionar; por otro lado la psicología social extiende este conocimiento a factores externos que influyen en el comportamiento del consumidor.

Así, la psicóloga y especialista en psicología del consumidor María Inés Vélez (2011) expone que "[...] cuando se habla de psicología del consumidor se habla de cultura, de construcción de roles, de percepciones, tradiciones, creencias y de presiones sociales". Y que además se basa en construcciones que el individuo mismo se hace de la experiencia de compra dada por la marca, y por otros factores como la publicidad, el marketing, el mercadeo relacional y el voz a voz. La psicología del consumidor es un área de estudio tanto individual como grupal y social.

La psicología entonces atraviesa aquellos aspectos económicos, sociales y culturales en los que se encuentra inmerso el consumidor y que de una u otra manera modifican su conducta de consumo.

Conviene decir que este conocimiento del consumidor busca disminuir riesgos al momento de crear estrategias de mercadeo. Con el estudio del individuo en toda su complejidad, las marcas no solo podrán crear vínculos racionales con el consumidor, sino también vínculos emocionales que generen actitudes positivas en él frente a las marcas.

\section{Aporte teórico de la estética en el estudio del comportamiento del consumidor}

Mandoki (2006) define la Estética como "[...] el estudio de la condición de la estesis, entiendo por esta a la sensibilidad o la condición de apertura o permeabilidad del sujeto al contexto en que está inmerso" (p. 15). Esta autora, además, plantea la condición del ser vivo expuesto al mundo, a la vida y al entorno, y su atracción por elementos según su especie y capacidad.

Según Mandoki (2006), la estética como disciplina examina la bio-estética como el estudio de la estesis en los seres vivos, y la socio-estética como el estudio de las prác- 
ticas estéticas en la vida social. La bio-estética, por su parte, habla de una "estética de la existencia" y entiende por este concepto el modo de llevar una vida armónica o bella, llevando a reconocer que la estética no se circunscribe solo a los estetas o artistas. De otra manera, la socio-estética se enfoca en dos campos de estudios: la poética como las prácticas de producción y recepción estética en el arte, y la prosaica entendida como las prácticas de producción y recepción estética en la vida cotidiana.

El común denominador de las teorías estéticas es la disposición del sujeto para la receptividad o percepción, donde se estudian términos como lo subjetivo, lo sensible, la experiencia y lo estético. "[...] lo estético es lo sensitivo. La sensibilidad va siempre unida a los sentidos, a las percepciones y a los sentimientos (Acha, 1998, p. 1. ).

De lo planteado anteriormente y para vislumbrar la función de la estética como aporte al estudio del concepto del consumidor es necesario analizar cómo la sensibilidad, la receptividad y la percepción determinan los comportamientos o decisiones de compra. El publicista Mario Zapata White (2011) en entrevista señala que conceptos como "[...] la cultura, la experiencia, el gusto, el deseo y la satisfacción", pueden relacionarse con el comportamiento del consumidor, y por su parte la cultura puede ser entendida como todo "[...]lo que el individuo aprende: lengua, creencias, prácticas, gustos"; representada como "[...] la memoria del cuerpo".

Es necesario resaltar aquí que cada cultura plantea o modifica sus estándares estéticos; los parámetros estéticos aceptados varían de acuerdo con cada cultura y esto puede denominarse subjetividad o cultura estética. De esta forma Acha (1998) explica la estética diciendo que esta:

[...] Se concreta en cada sociedad, época o individuo, adquiriendo rasgos particulares que pueden tener alguna de estas tres definiciones: suma de sentimientos e ideales de belleza, tanto humana como natural y de objeto; reunión de preferencias, aversiones e indiferencias sensitivas; conjunto de relaciones sensitivas o estéticas que mantiene el hombre con su realidad cotidiana (p. 1).

En esta configuración de la estética, hablamos del concepto "intercambios estéticos" que para Mandoki (2006) son: "los procesos de sustitución o conversión, equivalencia y continuidad en las relaciones que el sujeto establece consigo mismo, con los otros y con su entorno a través de enunciados que ponen en juego identidades individuales y grupales en términos de su valorización" (p. 26).

Según Lévi-Strauss, citado por Mandoki (2006) existen varios tipos de intercambios estéticos: económico (bienes y trabajo), matemático (valores numéricos), semiótico (mensajes, discursos, signos o enunciados), libidinal (deseos, flujos y placeres sexuales) y estético (estrategias y efectos sensibles) que pueden mezclarse entre sí.

El individuo en sociedad e inmerso en una cultura, se entreteje por medio de estos intercambios estéticos, y estos, se separan, se mezclan y se superponen dependiendo de cada situación. En el consumo, por su parte, desde el mercadeo y la publicidad, se hace alusión a estos intercambios dotados de simbolismo adaptados en los mensajes. Cuando 
se habla de mensajes, de su interpretación y su modo de comunicarlos, se refiere a la retórica como acto concreto en el intercambio estético.

Mandoki (2006) expone que la retórica está constituida por 4 canales de intercambios estéticos:

(1) Léxico: sintagmas verbales, sean orales o escritos, números, signos y códigos. (2) Somático: despliegue corporal, los gestos, la postura, la expresión facial, el olor, la temperatura y talla del cuerpo. (3) Acústico: la entonación, el volumen, el timbre y textura de la voz. (4) Escópico: visual, espacial, topológico, escenográfico, utilería y vestuario.

Partiendo de estos intercambios estéticos y de los canales por los cuales estos se suceden, en el mercadeo uno de los objetivos buscados es intentar producir en el consumidor ciertos efectos, y es aquí cuando se habla de estrategias estéticas, "[...] lo que el anunciante pretende lograr a través de tales estrategias son efectos de credibilidad, autoridad, cariño, simpatía, integración confianza, ternura, poder, que constituyen el ethos del anunciante y que el destinatario puede conceder, negociar, rehusar.

El sujeto sensible percibe y define el mundo a través de su cuerpo y de sus sentidos; en mercadeo uno de los canales de intercambios estéticos más explorados es el canal escópico (visual), y la imagen ha sido uno de los aspectos preponderantes e influyentes en el comportamiento del consumidor, pues de cierta manera moldea la percepción. La percepción se forma por la experiencia visual que una persona tiene respecto a un objeto o una situación, y esta puede generar sensaciones negativas o positivas. Dubois (1998) define la imagen como:

Un conjunto de percepciones que un consumidor tiene de un producto, de una empresa, de una persona o de una idea. Estructuralmente, la imagen toma la forma de una constelación de asociaciones entre el estímulo y un número variable de atributos discriminantes (p. 59).

La percepción se convierte entonces en toda esa entremezcla de intercambios estéticos. Por esto, una de las oportunidades que brinda esta área de conocimiento, es que las marcas y productos pueden explorar elementos como la sensibilidad estética para producir efectos positivos en los consumidores a través de los sentidos, que actualmente se está explorando como marketing de experiencias.

Los elementos de la estética son determinantes en el mercadeo para persuadir, motivar e impactar, ya que los consumidores no solo funcionan bajo la lógica de argumentos racionales. La construcción estética permite el intercambio simbólico de estilos de vida, de identidades grupales e individuales, de experiencias y de sensaciones. "El consumo constituye el proceso de satisfacer nuestras necesidades estéticas y, al igual que un pequeño motor, funciona constantemente y de muy variados modos en la sensibilidad de millones de personas, manteniendo viva la cultura estética de la sociedad" (Acha, 1998, p. 84).

El consumo, además interviene, modifica y plantea parámetros estéticos "[...] Las personas no compran productos solamente por sus prestaciones sino también por lo que el producto significa socialmente, por su forma, por su color, por su nombre $[. . .]^{\prime \prime}$ (Dubois, 1998, p. 19). 


\section{Conclusiones}

- El estudio del concepto del comportamiento del consumidor es complejo y requiere la intervención de otras disciplinas que permitan vislumbrar y abordar al individuo desde aspectos internos y externos. Por esto se dice que su abordaje es interdisciplinar y se debe retroalimentar con áreas que analicen el comportamiento del individuo desde diversas perspectivas.

- La conceptualización del consumo no puede supeditarse tan solo a momentos de compra; este debe ser estudiado como un acto social y colectivo, que permite intercambios simbólicos. El consumo es considerado como un acto social y colectivo, ya que responde a fenómenos culturales, que influyen, moldean y determinan estilos de vida, actitudes, comportamientos, intereses por medio de las interacciones grupales y/o sociales. En el consumo como acto colectivo intervienen aspectos psicológicos, económicos, sociológicos, culturales y estéticos, que constantemente permeabilizan al consumidor y sus decisiones o elecciones en cuanto a productos y marcas.

- El aspecto psicológico del individuo es permeado por lo económico, lo social y cultural. De esta manera el estudio del comportamiento del consumidor desde la vertiente interna no puede alejarse de todo lo que rodea al individuo.

- Se puede decir que el marketing se fundamenta en las necesidades humanas. Las necesidades constituyen la esencia del concepto de marketing. La clave de la supervivencia de una organización en un mercado depende de su capacidad para identificar y satisfacer las necesidades insatisfechas de los consumidores de la mejor manera.

- Cultural y socialmente, el consumo está cargado de simbolismo; por esto los individuos atribuyen a productos y marcas ciertos significados, que de alguna manera permiten la jerarquización social y la formación de grupos. De aquí que el consumo de determinados productos pueda incluir o excluir a los individuos de determinados grupos sociales. El consumo establece estructuras sociales jerarquizadas, que responden al tipo de producto que se consume, a la capacidad económica, la cultura, los gustos y los intereses.

\section{Bibliografía}

Acha, Juan. (1998). El consumo artístico y sus efectos. México, D. F.: Editorial Trillas, S.A de C.V.

Alonso, L. E. (2005). La era del consumo. Madrid: Siglo Veintiuno.

Alonso, R. (1971). Sociedad de consumo o civilización del bienestar. Buenos Aires: Gráficos Cadal.

Appadurai, A. (1991). Traducción de Argelina Castillo Cano. La vida social de las cosas. Perspectiva cultural de las mercancías. México: Gribaldo.

Armstrong, P. K. (2007). Marketing. México: Pearson Educación.

Assael, H. (1999). Comportamiento del consumidor. Sexta edición. México: International Thomson Editores. 
Batista, J. E. (1982). Escala de actitudes, para la investigación sociológica, psicológica y pedagógica. Medellín: Editorial Copiyepes.

Baudrillard, J. (1985). Traducción: Francisco de González Aramburo. El sistema de los objetos. Edición 8. México: Siglo Veintiuno.

Baudrillard, J. (1974). Traducción Rosa M. Bassols. La sociedad de consumo. Sus mitos, sus estructuras. Primera edición. Barcelona: Plaza y Janes S. A.

Bauman, Z. (2011). Traducción: Albino Santo Mosquera. Mundo consumo: Ética del individuo en la aldea global. Primera edición. Buenos Aires: Paidós.

Bauman, Zygmunt (2007). Vida de consumo. Traducción de mirta Rosenberg y Jaime Arrambide. México: Fondo de Cultura Económica.

Beals, A.R, George y Spindler L. (1971) Antropología cultural. Universidad de Standford 1967 by holt, Rinehart and Winston, Inc. Traducido por Hernando Asayuz. Primera Edición en español. México: Editorial Pax.

Becerra, R. (1994). El problema es... una sociedad de consumo irracional. Bogotá: San Pablo.

Buzzell D. R. y Levitt, T. Mercadotecnia: Un análisis contemporáneo. México: Continental, 1979.

Dogana, F. (1984). Psicopatología del consumo cotidiano. Primera edición. Barcelona: Gedisa S. A.

Dubois, B. y Rovira Celma, Alex. (1998) Comportamiento del consumidor. Segunda edición. Madrid: Prentice Hall Iberia.

Fairchild, H. P. (1944). Diccionario de sociología. México: Fondo de Cultura Económica.

Ferber, R. y Wales, H. (1969) Motivaciones del consumo en el Mercado. Segunda edición. Barcelona: Editorial Hispano Europea.

Galeano Marín, M.E. (2009). Estrategias de investigación social cualitativa. Primera edición. Medellín: La Carreta Editores E. U.

Geertz, C. (1973). Traducción al castellano Alberto Bixio. La interpretación de las culturas. Barcelona, España: Editorial Gedisa, S. A.

Hawkins, B. C. Y Addison, W. (1994) Comportamiento del Consumidor, Repercusiones en la estrategia de Marketing. EE. UU: Editorial Iberoamericana.

Jan de Vries. (2009). Traducción al castellano: Luis Noriega. La revolución industriosa: consumo y economía doméstica, desde 1650 hasta el presente. Barcelona: Crítica

Katona, George. La sociedad de consumo de masas. Madrid: Rialp 1968.

Kotler, P. (2007). Marketing: versión para Latinoamérica. Edición 11. México: Pearson.

Lipovetsky, G. (2007). Traducción: Antonio Prometeo Moya. La felicidad paradójica. Ensayo sobre la sociedad de hiperconsumo. Barcelona: Anagrama.

Mandoki, Katya. (2006). Prácticas estéticas e identidades sociales: Prosaica II. Primera edición. México: Siglo xxi editores, S.A de C.V.

Munné, F. (1986). Psicología social. Edición 3. Barcelona: CEAC.

Nanda, S. (1980) Antropología cultural. Versión en español de la obra Cultural Anthropology. La edición original publicada por D. Van Nostrand Company, New York, EE. UU.: Editorial Wadsworth international / Iberoamerica. 
Peter, J. P. y Olson, J.C. (2006). Comportamiento del consumidor y estrategia de marketing. Séptima edición. México: Mcgraw Hill. Interamericana.

Rivas, J. A. (2001). Comportamiento del consumidor. Madrid: ESIC.

Rivera Camino, J. Arellano Cueva, R. y Molero Ayala, V. (2009). Conducta del consumidor: estrategias y tácticas aplicadas al marketing. Segunda edición. Madrid: ESCIC

Robbins L. (1932). Ensayo sobre la naturaleza y significación de la ciencia económica. The London School of Economics.

Sanín Santamaría, J.D. (2008). Estéticas del consumo: Configuraciones de la cultura material. Medellín: UPB.

Schiffman, L.G. y Kanuk, L.L. (1997). Comportamiento del consumidor. Quinta edición. México: Prentice hall hispanoamérica.

Schiffman, L.G. y Kanuk, L.L. (2010). Con la colaboración de Josph Wisenblit. Comportamiento del consumidor. Décima edición. México: Pearson.

Schultz, D. E, Tannenbaum, S.Ly Lauterborn, R. (1992). Comunicaciones de marketing integradas. Bacelona: Granica.

Signorelli, A. (1999). División de ciencias sociales y humanidades. UAM- Iztapalapa Primera edición. Rubí, Barcelona: Anthropos editorial.

Solomon, M. R. (2008). Comportamiento del consumidor. Séptima edición. Naucalpan de Juárez: pearson.

Valiñas, R. F. (2002). Fundamentos de mercadotecnia. México: Thomson.

Verdú, V. (2003). El estilo del mundo. Barcelona, España: Editorial Anagrama. 